\title{
A phenomenology of subjectively relevant experiences induced by ayahuasca in Upper Amazon vegetalismo tourism
}

\author{
TOM JOHN WOLFF ${ }^{1}$, SIMON RUFFELL ${ }^{2}$, NIGEL NETZBAND ${ }^{3}$ and TORSTEN PASSIE TI $^{4,5}$
}

\author{
${ }^{1}$ Institut für Public Health und Pflegeforschung, Abteilung 6 Gesundheit und Gesellschaft, University of Bremen, Bremen, Germany \\ ${ }^{2}$ The Institute of Psychiatry, Psychology and Neuroscience, King's College London, South London and The Maudsley NHS Foundation \\ Trust, London, UK \\ ${ }^{3}$ University of West England, Bristol, UK \\ ${ }^{4}$ Dr. Senckenberg Institute for History and Ethics in Medicine, Goethe-University, Frankfurt/Main, Germany \\ ${ }^{5}$ Hannover Medical School, Germany
}

(Received: August 24, 2018; accepted: February 20, 2019)

\begin{abstract}
Aims: This heuristic study reports observations on the phenomenology of ayahuasca experiences of nine foreign tourist participants of an ayahuasca retreat in Peru. Methods: Narrative interviews, reflecting individual experiences after ayahuasca "night ceremony," have been analyzed by qualitative content analysis using a data-driven strategy in order to extract themes and categories inherent in the interviews. Previously, a demographic questionnaire was given. The dose-response connection was uncontrolled, which is typical for this naturalistic setting. Results: The typical structure of spontaneously reported experiences includes: personal preparation, physical symptoms, visual phenomena, cognitive and emotional phenomena, reactions of the individual within the psychedelic "world" as well as within ordinary reality, and appraisal to the process. Emotional reactions were subsumed under pleasant (psychotherapeutic "target emotions" and hedonistic emotions) and unpleasant emotions. For a majority, the presence of psychotherapeutic target emotions seemed to involve the presence of unpleasant emotions in the same session - possibly as transitional emotional states. Conclusions: This suggests that psychodynamic processes, for example, possible activation of emotional conflicts - can take place spontaneously, during ayahuasca intake in this particular setting. Some participants attributed symbolic meaning to the visionary content, which was more likely to take place in psychotherapeutically motivated clients. The specific setting influence as well as corresponding expectations of the participants in native wisdom could have considerable influence on experiences and interpretations, such as communication with entities as well as receiving personal teachings.
\end{abstract}

Keywords: ayahuasca, DMT, phenomenology, qualitative research, hallucinations, subjective experiences

\section{INTRODUCTION}

Over the past 20 years in Peru, ayahuasca tourism has developed into a thriving business (Grunwell, 1998). Several studies have assessed the reasons of use and found that this is in part due to the increasing demand from western tourists for experiences that can offer spiritual insights and epiphany, emotional catharsis, psychosomatic healing, and an "adventurous experience" (De Rios, 1994; Fiedler, Jungaberle, \& Verres, 2011; Fotiou, 2010; Hudson, 2011; Kristensen, 1998; Losonczy \& Mesturini, 2010; Schmid, 2010; Winkelmann, 2005; Wolff, 2018).

"Ayahuasca" is a Quechua word for South American beverages containing several species of the vine Banisteriopsis (B. caapi and B. muricata). It often also includes Psychotria viridis or Diplopterys cabrerana leaves, which cause psychoactive experiences sought out in psychedelic ethno-tourism. That psychoactive effect is also part of traditional healing practices in the Upper Amazonian vegetalismo (Beyer, 2009; Incayawar, 2007; Luna, 2005). $N, N$-Dimethyltryptamine is a naturally occurring psychoactive compound that mainly affects the serotonergic system in the CNS. The reversible MAO-A-inhibiting indolalkaloids - harmine, tetrahydroharmine, and harmaline prevent it from being deaminated in the digestive tract (McKenna, Towers, \& Abbott, 1984; Riba, 2003). During the peak plasma level of DMT, ayahuasca drinkers are known to experience vivid and colorful imagery, changes to their thought processes, and a state of heightened awareness. Perceptual and "inner experiences" - mainly cognitive and emotional - undergo changes while the sensorium remains intact (Callaway et al., 1999; Grob et al., 1996;

\footnotetext{
* Corresponding author: Tom John Wolff, Dipl.-Psych., PhD candidate; Institut für Public Health und Pflegeforschung, Abteilung 6 Gesundheit und Gesellschaft, University of Bremen, P.-Cornelius-Str. 31, 18969 Rostock, Bremen, Germany; Phone: +49 1764565 4209; Fax: +49 4212189868 880; E-mail: tiofijo@gmx.de
}

This is an open-access article distributed under the terms of the Creative Commons Attribution-NonCommercial 4.0 International License, which permits unrestricted use, distribution, and reproduction in any medium for non-commercial purposes, provided the original author and source are credited, a link to the CC License is provided, and changes - if any - are indicated. 
Riba et al., 2001). Nausea, vomiting, and diarrhea are the common effects of drinking ayahuasca, sometimes categorized as side-effects or "adverse symptoms" in pharmacological literature (Riba, 2003, p. 57); however, for many ayahuasca practitioners, these effects, along with their corresponding visual, synesthetic, emotional, and interpretative experiences, are considered to be intended main effects since the beverage is often called "la purga" (Spanish: the purge; Beyer, 2009, pp. 209, 213-214; Labate \& Pacheco, 2011; Shanon, 2014, pp. 62-63).

Members of the Brazilian ayahuasca churches "Santo Daime" and "União do Vegetal" have reportedly experienced "extraordinary visuals, kaleidoscopic lights, geometrical forms, tunnels, animals, humans and supernatural beings coinciding with sensations of peace, harmony and inner calm" (Barbosa, Giglio, \& Dalgalarrondo, 2005). Synesthetic phenomena such as simultaneous visions, sounds, and smells have also been reported (Luna \& Amaringo, 1999). Shanon (2002, p. 431) found that animals, phantasmagoric creatures, royalty and religious figures, magic and art objects, and divine beings are often reported. Autobiographical content appears to occur less frequently for experienced drinkers (Shanon, 2002, p. 432) but can reveal patterns of personality to the drinker (Shanon, 2002, p. 114). Benny Shanon provides a typology of visions that includes two-dimensional pop art or comic book style imagery, complex geometry and architecture with fluorescentcolored lines, expansive panoramic views of landscapes and worlds, visuals in the style of the painter Henri Rousseau, as well as baroque style or "fairy tale" visual experiences (Shanon, 2002, pp. 96-97). He also describes interactions with phantasmagoric beings (Shanon, 2002, p. 97). Some individuals, however, reported few or no visions (Shanon, 2002, pp. 96-98).

The appearance of supportive entities (Beyer, 2009, pp. 239-244; de Rios, 1972; Luna, 1986) and receiving teachings from the personified ayahuasca have been reported following traditional ayahuasca ingestion. The reports of these "teachings from entities" play a significant role in traditional Upper-Amazon vegetalism (Beyer, 2009, pp. 110-111; Luna, 1986; Shanon, 2014, pp. 65-67). It also has been reported to occur in an ibogaine-induced state of consciousness (Schenberg, 2013) as well as occasionally from western substance-supported psychotherapy, for example, guiding spirits from family members during psilocybin ingestion (Belser et al., 2017, pp. 365-366). Psilocybin and (to a lesser extent) ketamine are also known to produce similar complex imagery (Studerus, Gamma, \& Vollenweider, 2010). This may indicate the significance of individual circumstance and the setting in which psychoactive substances are ingested, in terms of influencing similar perceptional content.

To clarify, for the purpose of this paper, we will be distinguishing visions from hallucinations. Hallucinations, in contrast to the visions induced by ayahuasca, give the subjective impression that what is being seen is a part of reality, to the extent that the person can hardly distinguish between a shared reality and the hallucinatory experience.

In a study using semi-structured questionnaires, Kjellgren, Eriksson, and Norlander (2009) found that when reflecting on the process of experiencing an ayahuasca trip, participant's reports included the following stages: (a) motivation to take ayahuasca (prior to ingesting), (b) contractile frightening state, (c) a sudden change or transformation of the experience, (d) a limitless expansive state with transpersonal experiences, (e) reflection on the experience, and (f) changed worldview and new orientation to life. The final stage of the process feeds back into the first stage, as at this point they are able to recognize the potential psychotherapeutic benefits.

Based on analyses of a great number of LSD and mescaline trips, Masters and Houston (1966) described a general psychedelic model of depth stages: (a) sensory stage with perceptual changes and altered awareness of the body; (b) recollective-analytic stage with in-depth thinking about personal problems, relationship problems, life goals, past experiences, and emotional abreactions; (c) symbolic stage with visualized landscapes and architecture, historical, mythic, ritualistic, and archetypal scenes and communication with beings; and (d) integral stage with transcendent and mystical experiences.

As Franquesa et al. (2018) point out, documented improvements in different pathologies have been attributed to the introspective qualities of ayahuasca, although the possible underlying psychotherapeutic processes are not yet well understood. Anecdotal benefits often include dissolution of the ego, a reprioritization of what is important, understanding oneself better, improved ability to understand others, acceptance of oneself and past life events, and personal growth (Bresnick \& Levin, 2006 quoted in Franquesa et al., 2018).

Mystical experiences such as oneness, ego-dissolution, and connectedness may predict a long-term increase in well-being, as well as clinical improvements after psychedelic therapies (Carhart-Harris \& Goodwin, 2017; Griffiths, Richards, McCann, \& Jesse, 2006). Carhart-Harris, Erritzoe, Haijen, Kaelen, and Watts (2018) believe that a feeling of connectedness is a key factor for good mental health. There is evidence that a feeling of connectedness facilitates psychological well-being (Cervinka, Roderer, \& Hefler, 2012), and that a sense of disconnectedness is a factor in depression (Karp, 2017). Experiences of connectedness have commonly been reported by people who have used ayahuasca (Shanon, 2002, p. 205).

Franquesa et al. (2018) found evidence of therapeutic processes in ayahuasca inebriations, which are also known in other psychotherapies: decentered introspection, attribution of meaning (which was also proposed by Shanon, 2003) as well as alterations in meaningful, guiding values in life (also discussed by Kavenská \& Simonová, 2015; Liester \& Pricket, 2012 and others). Some psychedelic therapies aim to create "meaningful visual phenomena," as well as changes to the personal narratives of patients (Belser et al., 2017, p. 372). Concepts of generating and altering meaning are common in psychotherapy and have been described under various terms (see Batthyany \& Russo-Netzer, 2014; Cade, 1992; Frankl, 1986; Lichtenberg, Lachmann, \& Fosshage, 2016; Mattila, 2001; Mittelmark et al., 2017; Roediger, 2011; Ruf \& Schauer, 2012; Yalom, 1980). They have also been generalized as a psychotherapeutic effect factor; "new selfnarration" in a broader sense is defined as the development of a coherent rewording of the patient's life history, as well as a new assessment of their identity and relationship to the environment (Jørgensen, 2004). 
Emotional release is not only a typical effect of ayahuasca (Shanon, 2014, p. 64), but also of other psychedelics such as LSD and psilocybin in psychotherapeutic settings (Belser et al., 2017; Gasser, Kirchner, \& Passie, 2014). It indicates typical process-elements that have been previously described from therapies with entactogens, and are typically accompanied by emotional activation; "acceleration of psychological processes," "regression," "rescripting of past behaviors," "problem actualization and corrective new experience," as well as "transpersonal experiences" (Passie, 2012). Emotional release is seen as closely related to meaningful experiences, especially those described as "alternative simulations of formative situations from the past, encapsulated in an inner realm" (Passie, 2012).

Gaining diagnostic insight into other peoples' social and psychosomatic issues may be of particular interest in medical anthropology, as ethnographic literature documents that local vegetalistas of the Amazon claim to gain insight into the causes of the diseases through ayahuasca (Luna, 1986), diseases often being thought of as physical symptoms of social ills (Beyer, 2009, pp. 178-180).

Due to the study's heuristic aim and qualitative paradigm, no particular explicit hypothesis was tested. The heuristic study aims to contribute to the investigation of the phenomenology of ayahuasca in western clients, as well as possible implications for psychedelic-assisted psychotherapy. For this, the study aims to explore more comprehensively, the common structure of acute subjective experiences and emotions elicited by ayahuasca in the context of ceremonial western ayahuasca tourism in the Amazon.

\section{METHODS}

\section{Ethics and confidentiality}

An informed consent form about participation in the study was signed by all participants prior to starting the retreat. Only individuals who had already booked the retreat independently of the study were invited to participate. Participants were not invited to ingest ayahuasca specifically for this study.

Confidentiality and the voluntary nature of participation was assured and reiterated throughout the research and publishing procedure. The procedure was aligned with the Declaration of Helsinki - Ethical Principles for Medical Research Involving Human Subjects (WMA, 2013). BPS guidelines have been followed throughout the study design.

\section{Sampling and recruitment}

This investigation took place at the Ayahuasca Foundation facility located in the Amazon rain forest near the Peruvian town Iquitos (https://www.ayahuascafoundation.org). It is a typical "healing center," run by an US-American apprentice of a local vegetalista, offering shorter and longer ayahuasca retreats for western clients, as many other centers in the region do. Initial contact was established via an Internet search. All nine participants were asked at the beginning of the 13-day period whether they would be happy to be interviewed during the retreat, which they agreed to.

\section{Procedure}

Upon signing the informed consent form, a demographic questionnaire was completed. Six ayahuasca ceremonies were conducted in group settings at night. Interviews took place in the morning, immediately after the second ayahuasca night ceremony had finished.

\section{Qualitative interviews}

A narrative interview strategy was chosen (Helfferich, 2011, p. 114; Küsters, 2009) to minimize any potential bias or leading questions relating to the study (Patton, 2002, p. 39). This meant that we were able to identify the elements that were subjectively most relevant to participants, as they were self-reported by the interviewee without prompting. Participants were asked to report what they had experienced during the ceremony, for example, "please tell me about your experiences during the ceremony as openly as possible." An open question about emotional experience was subsequently added to the narrative interview since, in contrast to traditional local ayahuasca use in the upper Amazon region (de Rios, 1972; Luna, 2004), the focus of the providers of ayahuasca for western clients is on psychotherapeutic processes of "emotional purging" and "emotional healing" (Beyer, 2009, p. 348). Interviews were sound-recorded.

\section{Method of analysis}

Participants reported their experience of ayahuasca with minimal prompting from interviewers during narrative interviews. We surmise that more frequently mentioned elements of the experience may have more subjective value to the participants than those seldom or not mentioned at all. The coding frame aims to identify the commonly shared inner structure of the analyzed narratives, and the coding frequencies represent the subjective importance or relevance for the narrators.

After transcription, interviews were analyzed through qualitative content analysis (QCA) using a mixed datadriven strategy. A progressively paraphrasing strategy was combined with a subsuming strategy (Schreier, 2012, pp. 115-120). For the first interview, the material was cut into single statements; all statements (coding units) were paraphrased, in order to build up provisional main categories. Similar paraphrases with shared meaning were paraphrased again. In this way, abstract categories were formed. For the additional material, statements were used to build up subcategories, and further statements were either subsumed under these already existing subcategories or new subcategories were formed. The coding-frame was built up successively until a point of saturation was reached. After the ninth interview, no further categories had to be introduced in order to classify new material. In qualitative research, it is not yet fully possible to calculate reliability indices. Content analysis conceptualizes reliability through consistency. Consistency is operationalized either through the level of intersubjective rater agreement or stability over time. The concept is related to the plausibility of the interpretation (Schreier, 2012, pp. 167-175). In order to ensure reliability, the material was completely recoded by the same coder after 
a period of 3 weeks, and the percentages of agreement and Cohen's ks were calculated for each category. Both are common criteria in qualitative research. All of the compared categories were found to be reasonably consistent $(94.91 \leq$ Percentage $\left._{\mathrm{A}} \geq 100 ; 0.43 \leq \kappa \geq 1\right)$. Categories were also analyzed in terms of how often they were discussed by the different participants (how many participants talked about a certain theme), as well as coding units (number of statements about a particular topic compared with the overall number of statements).

\section{Characteristics of participants}

The ages ranged between 27 and 71 years $(N=9$, median $=33$, interquartile range $=10$ ).

- Gender: six males and three female participants.

- Previous experiences with hallucinogens: eight participants.

- Psilocybin: ("magic mushrooms") ranging from one trial to monthly use, and from 1-year use up to 10 years;

- LSD: ranging from one trial to monthly use, and from 1-year use up to 10 years;

- MDMA (Ecstasy): ranging from one trial to monthly use, and from 1-year use up to 10 years.

- History of psychotherapeutic consultations: five participants.

- Previous medical conditions such as hypertension, knee replacement, hypothyroidism, pneumonia, appendectomy, choroid ocular melanoma: six participants.

- Previous psychiatric conditions such as depression or anxiety disorder: three participants.

- Eight out of nine participants graduated from college or university. Reported professions: nurse, dietician, marine engineer, medical doctor, pharmacist, and psychologist.

\section{RESULTS}

The narrative structure of reports of ayahuasca experiences consisted of the overarching main topic, "experiences during the ceremony" (Figures 1-3), and two side categories: "preparedness" (Figure 1) and "appraisal of the process" (Figure 3). Often the narratives started with a short discussion about preparation for the experience, followed by a long discussion addressing the focus of the study, the actual experience of taking ayahuasca, and ending with an appraisal of the process. Reflecting the initial interview question, the most frequent statements made were about the actual experience. The internal structure - depicted in the coding frame - is complex and contains several themes, subthemes, and categories. It is presented category by category and also as a graphic overview (Figures 1-3, respectively).

\section{Preparedness}

Typical statements about personal preparedness were about motivation and the level of pre-knowledge. Overall, the topic was only touched on briefly.

\section{Appraisal of the process}

This side theme refers to the appraisal and general characterization of the experience as a dynamic process, which changes in intensity and quality over time. Sometimes, difficulties during the process were mentioned such as lack of control, unpredictability, and difficulties regarding the intensity or the speed of the perceived flow of psychedelic content.

Although not frequently, the role and influence of the shamanic singing on the experience was spontaneously mentioned by more than half of the participants. The ritual singing was reported to affect physical sensations within participants' bodies and influence visions, as well as help to direct attention and stimulate mood or energy changes. The shaman himself was adept at regulating the experience. As a setting variable, the singing was a modulating factor, affecting the intensity and quality of the psychedelic as well as physical experience. For this reason, we grouped it into this category.

\section{Experiences during ceremony}

The following themes and subthemes were subsumed under "experiences during the ceremony" (Figures 1-3). Note that most of the themes contain several subcategories that are presented later:

- physical symptoms;

- visions, hallucinations, properties of visions, and evaluation;

- intensified imagination and contemplative thoughts;

- received messages;

- attribution of meaning (immediate symbolic understanding and insights through own reflection);

- different types of meaning attributed to psychedelic content (interpersonal, relational, about other people's issues, general wisdom, mystical, spiritual, or religious content); and

- emotional and other psychological reactions of the individual, such as acting within and outside the visions, cognitive reactions.

\section{Physical symptoms}

The experience of physical symptoms as a result of taking ayahuasca is a common and frequent topic that was mentioned by all participants ( $12.43 \%$ of all statements; ranging from $3.13 \%$ to $37.14 \%$ per interview). Vomiting and nausea are the most common and frequently reported phenomena (seven and five participants) and as such, the subjectively most relevant physical symptoms. Changes in the quality of the experience with regard to visions, thoughts, and the level of inner agitation after vomiting were spontaneously reported by a minority (three of nine participants). Other physical symptoms reported include stomach pain, diarrhea, restlessness, tremor, raised temperature, fuzziness, exhaustion, heaviness, executive muscle problems, sensitized senses, and synesthetic-like experiences such as visualizing sounds. 

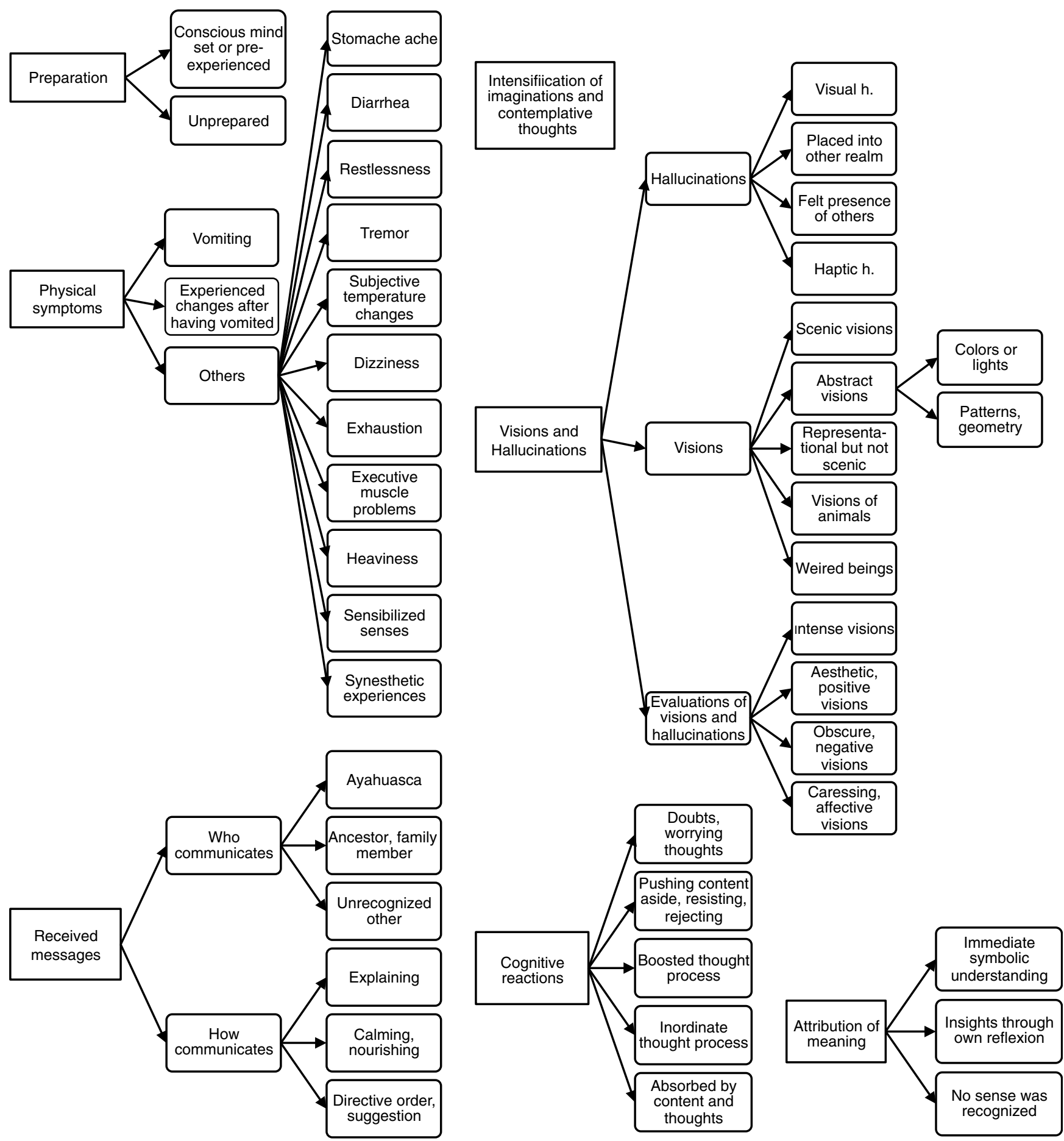

Figure 1. Preparation, physical symptoms, phantasies, visions, received messages, cognitive reactions, and attribution of meaning reported after a shamanic ayahuasca ceremony in the Amazon region in narrative interviews of nine foreign participants using qualitative content analyses

\section{Visions and hallucinations}

Visions were a common and frequent topic (eight of nine participants, overall statement frequency $=11.86 \%)$. We use the term visions because it is commonly used among ayahuasca users. Visions are vivid geometrical patterns, scenes, persons, creatures, and objects, most often perceived with closed eyes or in complete darkness. Visions can appear for a participant when their eyes are open, but are seldom. The ability to distinguish between visions and the perception of the surrounding reality remains intact in most cases. True visual hallucinations (seeing things that are not there) as well as hallucinatory misjudgments of real objects or persons (pseudo-hallucinations) do occur, but are less common and less frequent than visions (five participants, $4.52 \%$ of all statements). "Haptic hallucinations" refer to the sense of being touched or caressed in the absence of external stimuli. Other phenomena subcategorized into "visions and hallucinations" are the "felt presence of another person/ being," and the sensation of "being placed entirely into 

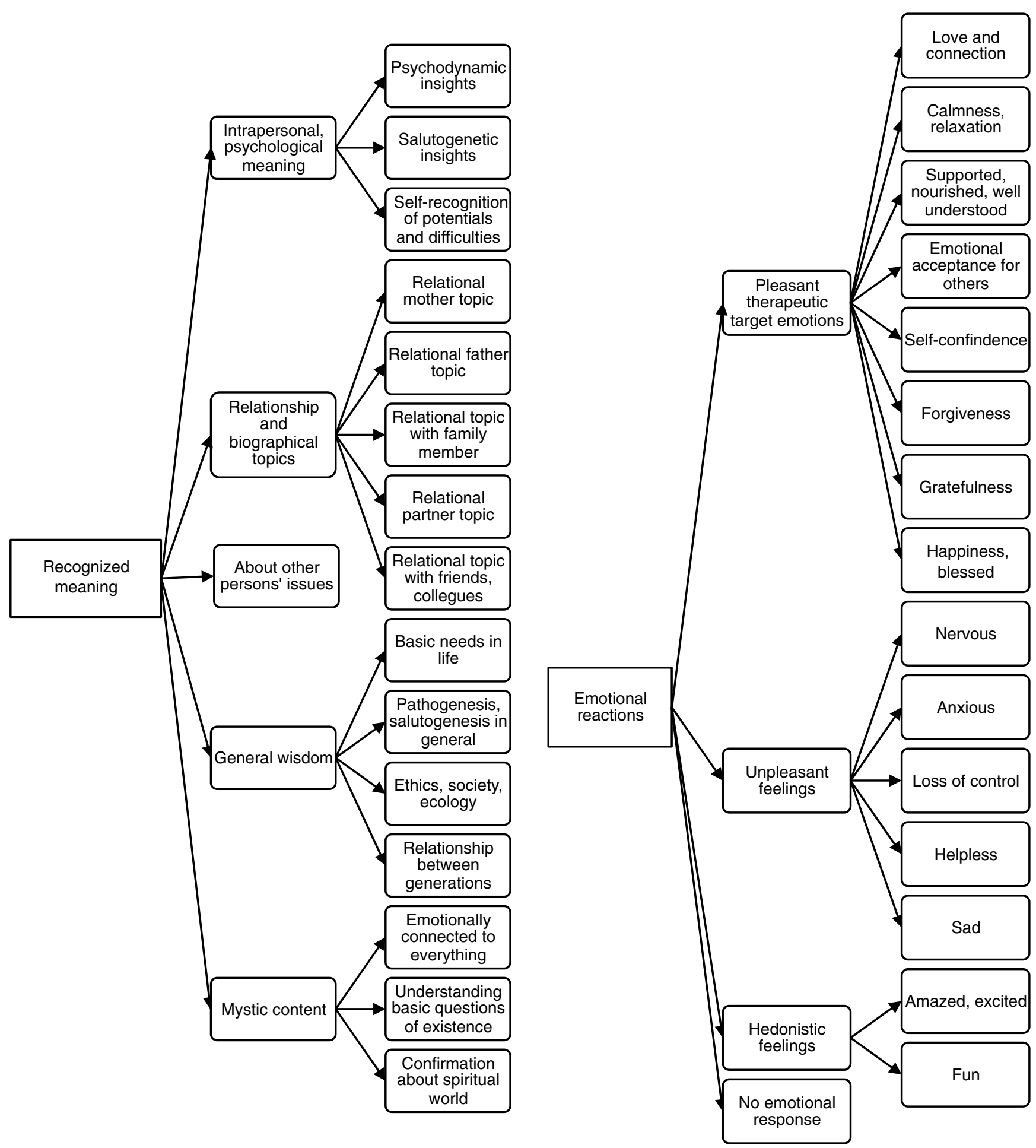

Figure 2. Recognized meaning of psychedelic content and emotional reactions reported after a shamanic ayahuasca ceremony in the Amazon region in narrative interviews of nine foreign participants using qualitative content analyses

another realm" for parts of the session. The visions and hallucinations were spontaneously evaluated as being intense, aesthetically positive, and affectively kind or obscure.

Abstract visions composed of colors, complex geometric patterns or symmetrical shapes were the most common type (eight participants, statement frequency $=5.65 \%$ ).

Other less common and less frequent types of visions reported included "representational objects" (one participant), "scenes and people" (three participants, frequency $=4.25 \%$ ), "animals" (one participant, frequency $=1.41 \%$ ), and "fantastic or weird creatures" (four participants, frequency = $1.13 \%)$.

No, just abstract, totally. No there was no connection between anybody at all. Not somebody I had seen in my life before or a love. Just to describe them is almost impossible. I wondered how the hell I could ever do that. And very vivid colors. But rather they were almost symmetrical in certain aspects, a lot of them. And it just looked so beautiful. (2) 

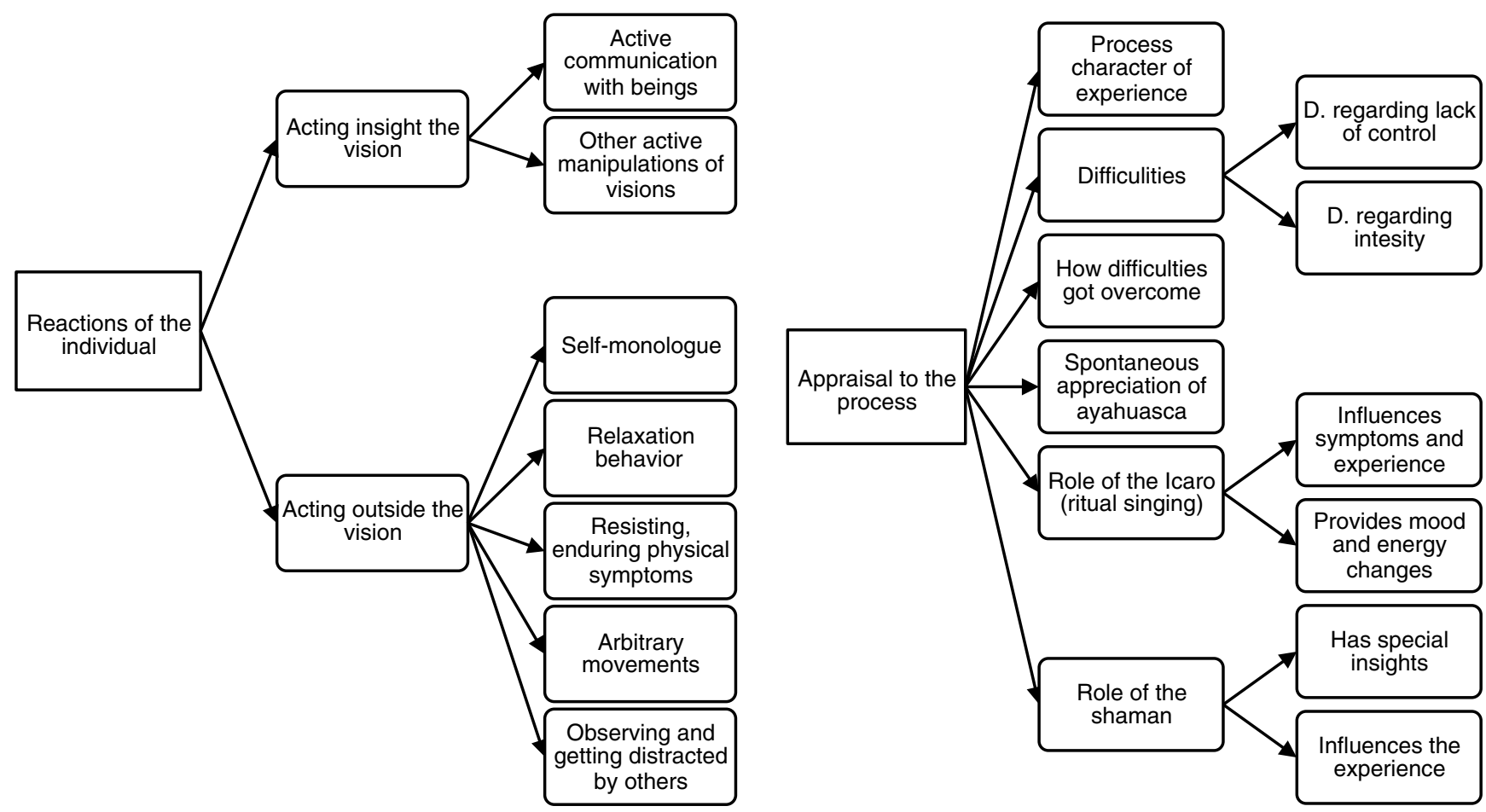

Figure 3. Appraisal of the process, role of ritual singing and of the shaman, individual reactions reported after a shamanic ayahuasca ceremony in the Amazon region in narrative interviews of nine foreign participants using qualitative content analyses

\section{Intensified imagination and contemplative thoughts}

Participants reported that thoughts and imagined experiences were intensified. They were able to make a distinction between visions and imagination or fantasies in general.

\section{Attribution of meaning}

In general, having meaningful experiences either through immediate symbolic understanding or through personal reflections during an ayahuasca ceremony was a common and spontaneously occurring phenomenon among our interviewees. Eight out of nine participants used altogether $7.91 \%$ of all coding units for this category. Eight out of nine interviewees found parts of the perceived material "insightful." A minority of three participants explicitly reported that they could not understand the meaning of specific content. The spontaneous recognition of content as symbolic was an uncommon phenomenon in the material. It occurred for one participant who stated:

And then suddenly it occurs to me this is just a symbol for my inner child. (1)

Insights as a result of intensified reflective processes during the ceremony were reported more often than recognizing content as symbolic:

And, me to kind of resolve, that just to move on with my life and just never have to think about that again and start, you know, a better relationship with somebody else. (3)

\section{Received messages}

Direct messages from "entities" were infrequent for most of the sample. They were concentrated with an overall statement frequency $=4.24 \%$ in three out of nine participants. One participant claimed to have received voice-like messages directly from "Mother Ayahuasca." Another participant received messages from a family member, and another from an unspecified entity. The subjectively perceived communication was received in an "explaining" or "teaching" style, as a therapeutic order or suggestion, or in a supportive and calming manner:

When I go into the medicine I have something I can hold onto, like jewelry or a stone or something. I also have this jewelry that is from my mum. I tried... it was somewhere on my mattress... I tried to find it because I thought I was to connect again to this sacred holy space [of her mother]. And I couldn't find it, I couldn't, oh my God, I want to find it because I want to connect, and suddenly I heard the voice of my mum and she says: You don't have to find anything, I am always here. I am always here. You just have to turn to me, towards me. And I am here anyhow, because I am your mum. My love is always here. You are the one who turned away. You are the one who decided to go away. The moment you turn around I am always here. (1)

\section{Recognized meaning of content}

Seven out of nine participants reported spontaneously gaining "insightful personal meaning" during the ceremony, with an overall statement frequency $=17.51 \%$. Five subthemes of meaning containing further subcategories were found in the material (Figure 2), including:

- interpersonal psychological insights: three participants, overall statement frequency $=4.52 \%$; 
- insights into relational, social biographic themes: six participants, overall statement frequency $=7.34 \%$;

- insight into motives or issues of other people: two participants, overall statement frequency $=.8 \%$;

- general social, ethical, healing of mankind, or environmental wisdom: four participants, statement frequency $=3.38 \%$;

- mystical, spiritual, and religious insights and experiences: five participants, overall statement frequency $=4.8 \%$.

Interpersonal insights point to the origin of personal problems and symptoms. This includes psychodynamic insights and personal learning history, salutogenesis, resolving psychosomatic problems, self-awareness and selfrecognition regarding personal potential, traits, and problems. In the following example, a participant received sudden and subjectively convincing revelations about a psychodynamic pathogenesis model of her eating disorder, after she had the highly affective vision of being caressed by her mother. She identified a hunger for emotional nourishment rooted in early childhood as a conflict that leads to compensatory eating and bonding behavior:

And then mother ayahuasca was telling me: This is the nourishment you are looking for. This is the reason why you eat too much. Even though you eat too much you never feel really fulfilled... This is the nourishment you are looking for ... and of course the medicine was just pointing out: 'this is the place.' You have to connect here, don't connect with a cat. That is just a substitute. It's not really what it is about. Don't connect with your husband. Your inner Child has to connect with your mum and from this space you get the nourishment that you need and then you can handle that your cat is dying or whatever. This is a special kind of nourishment. It can only come from there. (1)

Another participant reflected about a conflicting aspect of her personality without having any psychodynamic insights. She realized her ability to easily perceive the emotional states of others and explored its pros and cons. Finally, she could reframe this as a special ability rather than an exclusively problematic aspect:

The emotion? Empathy, I guess. I was very worried about the people around me, which is something I do way too much as a nurse. And I feel I have always done so - like when somebody is going through something or having hard times. Even with my patients, I struggle with that at work, because it is just like I feel if anyone gets sad or crying like oh I'm going to, I can just feel that. So that I just could feel that emotions around, going on around me, the emotions. I felt pretty happy. I was like: yeah, that is awesome. (4)

Two participants reported to have been preoccupied with their relationship with their mother. One person mentioned being preoccupied with a relational issue with their father and one person about relational issues with other family members. Partner issues were mentioned by three participants (overall statement frequency $=1.69 \%$ ) and relationships issues with friends, colleagues, or others were mentioned by four participants (overall statement frequency $=1.69 \%$ ).

"Mystical, spiritual, and religious content" is a collective category that refers to statements regarding experiences of oneness, global connectedness, overwhelming general empathy, sudden knowledge and understanding of existential questions and paradoxes, the impression of clarity and the confirmation and renewal of faith, and religious belief in the existence of a spiritual world beyond the mundaneness of existence:

But then I just drift off into something really obscure. I started getting quite profound insights into what I consider consciousness. Thinking about how we all are just fragments of something a lot bigger. (8)

And I started asking ayahuasca questions. Questions I think most people think about, like: why is there life on earth, what happens after you die? Questions you can never normally have an answer to. And I felt those questions were just answered immediately. The answers were kind of implanted into my brain. I remember just lying on my mat, thinking: how can this possibly be? (9)

It is true. I do not believe it is just hallucination. I believe that there is something real there. That there is some sort of real connection to the spiritual world. It confirms that there is probably something happening outside of this. Sometimes I do worry that, you know, we die, that there is just darkness and that the experience is just over. Ayahuasca is so profound, that one has to believe that we are, you know, that something is happening after this world, and that we all are connected. It brings a feeling of love and those things. (3)

\section{Acting inside the visions}

Two participants not only perceived but also directly responded to visual experiences. They acted within the visions in an attempt to communicate with entities (two participants) and interact with the perceived visionary content (one participant):

Because my mind was like: I do not want to be in one space with my mum. I want to eject my mum. And then the medicine told me, already showed me, there are different energy strings. And one is unconditioned mother love, then next to that, there is expectation and then next to this is one's own needs. The medicine told me that I have to find the string that is only mother-love. And I thought I could agree on that. So I found this string, which had a yellow and orange color. And it became a little seed, it looked just like a [grain of] rice (laughs). And it was like, 'you can take it or you cannot take it' and I think: ok I'm gonna put it in my heart. And from this moment somehow she said: 'feel it, feel it, feel it'. I felt like, ok this is the nourishment I am looking for, ok this is really good for me. (1)

I saw a little kind of joker being. And I asked him, as I was told to do, if it was medicine - to stay and if it was not 
medicine - to go away. And then I was transported into that really brightly colored

room ...(9)

\section{Acting outside the visions}

Acting outside of the visions was more commonly (eight of nine participants) and frequently reported (8.76\%). Typical actions included repeating words to self in a monologue, behavior that indicated relaxing such as changing into a comfortable position, resisting physical distress, for example, holding back vomit, arbitrary or general mannerism movements, and being attentive to other participants (Figure 3).

\section{Other cognitive reactions}

Cognitive reactions were common (eight out of nine participants) and frequent (overall statement frequency $=11.86 \%$; Figure 1). "Doubts and worrying thoughts" were moderately common (six participants) followed by "controlling and rejecting content" (five participants) and "getting absorbed" by the experience (four participants). "Intensified thoughts" or a flurry of ideas were less common (three participants). Only one participant mentioned an "inordinate thought process" during the ceremony.

\section{Emotional reactions}

Emotional reactions were mentioned by all participants (overall statement frequency $=18.64 \%$ ). It can be distinguished between therapeutically desirable emotional states, unpleasant emotional states, and hedonistic emotional states.

Pleasant and therapeutically desirable emotions have been found in the narratives of eight participants, overall statement frequency $=10.73 \%$ (Figure 2):

- "love and connection" (five participants);

- "calmness and relaxation" and "happiness and feeling blessed" (four participants);

- "gratitude" (three participants);

- "supported, nourished, well understood, and selfconfident" (two participants);

- "acceptance and openness to others" and "forgiveness" (one participant).

And somehow I could allow this sense of love - just rejected all the bullshit that my mum was carrying, and all the expectation. I just [left it] by the side and just concentrated $100 \%$ on this mother honey, the sense of it - holy. It even felt like being with her in a holy space that nobody can disturb and nobody can enter. And that is very unique in this world. (1)

Unpleasant emotions (nine participants, overall statement frequency $=5.37 \%$ ) were:

- "anxiety" (eight participants);

- "nervousness" (three participants);

- "loss of control or orientation," "helpless," and "sadness" (one participant each).
Typical hedonistic emotions, mentioned by four of nine participants (overall statement frequency $=2.54 \%$ ), were "amazement" (two participants) and "enjoyment" (one participant). Sexual content was not mentioned.

In eight of nine cases, unpleasant emotions appeared alongside therapeutically desirable emotions in the same ceremony. Four participants did not explicitly mention any emotional reactions (overall statement frequency $=1.7 \%$ ).

Participants 1, 5, and 9 described a pleasant and therapeutically productive experience, describing the resolution of inner conflicts, whereas Participant 4 described an emotional process with more unpleasant (sad, nervous, and worrying self-blame) as well as hedonistic emotions (fun and enjoyment, three statements), instead of desirable therapeutic emotion (empathy, mentioned once). She also twice mentioned the absence of emotion when she would have expected to feel something. Participant 2 reported no therapeutic target emotion whatsoever, alongside unpleasant and hedonistic episodes with the absence of emotion (Table 1).

\section{DISCUSSION}

The presented analysis helps to document in greater detail the phenomenology of altered states of consciousness in western ayahuasca tourists. Regarding visual phenomena, the categories of abstract, representational and scenic material, and animals and weird beings are in agreement with previous reports (Barbosa et al., 2005; Shanon, 2002). As already noted by Shanon (2014, pp. 67-69), ayahuasca drinkers usually find themselves in the role of spectator of visual phenomena; however, intense ayahuasca experiences can involve acting within the visions and even interactions with entities, such as relatives, ayahuasca itself, and phantasmagoric creatures. Personal teachings in an explaining or directive manner were reported to take place for some of the interviewees. Schenberg (2013) see psychotherapeutic potential in such directive messages from entities. The personal long-term impact of these teachings, their uncontrollable nature, as well as the possible role of individual expectations and the influences of the setting could be a topic of future research.

Our findings are consistent with previous literature in which dealing with physical stresses such as nausea and vomiting is dominant in ayahuascsa trip reports (Shanon, 2014, pp. 62-63). The same applies to ibogaine, but not to LSD, mescaline, and psilocybin (Schenberg, 2013). Hallucinatory auditory phenomena seem to be less common than in ibogaine ingestions (Schenberg, 2013).

Changes in the quality and intensity of the psychedelic process after vomiting have been reported. This points toward a possible bottleneck-like effect during ayahuasca ceremonies, which were previously described by Kjellgren et al. (2009) as "sudden transformation of the experience."

The interviews contain elements of all general depth stages of psychedelic experiences, from perceptual changes through mystical experiences (Masters \& Houston, 1966). Unfortunately, the narratives revealed little details about the temporal sequences of the reported phenomena, so that we can contribute only little to the phase-typical sequence of psychedelic depth stages with our unstructured method. 
Wolff et al.

Table 1. Distribution of statements of different emotional categories in narrative interviews of nine foreign participants of a shamanic ayahuasca ceremony in the Peruvian Amazon region

\begin{tabular}{lcccc}
\hline $\begin{array}{l}\text { Participant } \\
\text { no. }\end{array}$ & $\begin{array}{c}\text { Therapeutically } \\
\text { desirable emotions }\end{array}$ & $\begin{array}{c}\text { Unpleasant } \\
\text { feelings }\end{array}$ & $\begin{array}{c}\text { Hedonistic } \\
\text { feelings }\end{array}$ & $\begin{array}{c}\text { No emotional } \\
\text { response }\end{array}$ \\
\hline 1 & 9 & 3 & 0 & 0 \\
2 & 0 & 1 & 1 & 2 \\
3 & 1 & 2 & 0 & 0 \\
4 & 1 & 3 & 3 & 2 \\
5 & 9 & 1 & 1 & 1 \\
6 & 1 & 1 & 0 & 0 \\
7 & 2 & 3 & 0 & 1 \\
8 & 3 & 1 & 0 & 0 \\
9 & 12 & 4 & 4 & 0 \\
\hline
\end{tabular}

Intensification of imagination and contemplative thoughts was reported, previously also known in conjunction with deep "self-search" and psychological analysis, creativity, metaphysical ideas, and new personal perspectives (Shanon, 2014, pp. 69-70).

Some people were not able to infer meaning from these psychedelic experiences. For others, symbolic meaning was immediately evident without intellectual interpretation. Some interviewees reported to have gained personal insights through intensified thinking, which Shanon (2014, pp. 69-70) calls "mentation." We did not find this distinction in the previous literature; however, we consider it to be significant because of the unique ways individuals experience ayahuasca inebriations, and not least because of the high level of subjective persuasiveness that immediate symbolic understanding can have.

The narratives show that a moderate number of participants were able to increase their self-awareness about personal ability, traits, and difficulties. However, only one psychotherapeutically preexperienced participant explicitly reported psychodynamic insights into origins of personal issues, and one other reported salutogenic insight into solving personal issues. It does not appear self-evident in our interviews that ethno-psychedelic ayahuasca experiences lead to psychotherapeutic insights, which would automatically become integrated into an altered personal narrative about meaning and values. For some, it was simply a fascinating or bizarre adventure with no evidence of any impact on self-actualization, reframed perception of self, or new self-narration. Although the reason that it should occur in some cases over others is not clear, it may be a combination of reasons based on the heterogeneity of tourist participants; intention, cognitive style, personality, life-situation, and psychotherapeutic preparedness.

Ayahuasca tourism does not usually include post-session or post-retreat care. Subjectively relevant insights occur but immediate symbolic understanding does not seem to happen spontaneously in untrained individuals of our interviewed group. Individuals who do not have the immediate emotional and cognitive meaning-making of their inner images and visions may benefit particularly from further discussion after they have processed the experience in order to develop meaning-making and personal relevance during the integration phase. Particularly, since the generation and immediate understanding of symbolic material as meaningful (Belser et al., 2017, p. 372), as well as the later meaning-making
(Belser et al., 2017, p. 355), is central to modern psychedelic supported therapy. Therefore, the categorization of recognized meaning of psychedelic content in western ayahuasca drinkers seems to be of particular interest to us, that is, interpersonal psychological meaning, relationship, and biographical topics, about other persons' issues, general wisdom, and mystic content. These categories, except "about other people's issues," seem to relate to the health-related personal values and introspective processes previously mentioned in the literature (Franquesa et al., 2018).

The spontaneous appearance of relationship issues in a small majority of participants is consistent with previous ayahuasca reports from Shanon (2003). It was also observed in psychedelic experiences with other substances (Belser et al., 2017).

Participants reported a spontaneous emotional release as well as corrective emotional experiences. The high frequency of spontaneous mention of emotional responses in reports when using ayahuasca suggests a high subjective priority of emotions during and shortly after ingestion. A majority reported the appearance of pleasant as well as unpleasant emotions. Both seem to be a common part of the ayahuasca experience. Having "no emotional response" could be interpreted as a defense mechanism in psychoanalytic terminology. On the contrary, it could also be a sign of having overcome a conflict, emotional exhaustion, or of overload inhibition. Subjectively successful experiences of ayahuasca appear to be characterized by the presence of unpleasant emotions as an expression of the activation of relevant conflictive material and the inner struggle with it, as well as pleasant and desirable or "target" emotions with possible "salutatory impact" (Shanon, 2014, p. 64) as an expression of resolution.

Hedonistic feelings as well as emotional blockages, or the absence of emotional response to emotionally relevant material, seem less dominant. It is worth exploring the relationship between pleasant and unpleasant emotions within the same session in more depth, as a possible indication of therapeutically successful ayahuasca trips, possibly described as the aforementioned "sudden transformation of the experience" by Kjellgren et al. (2009).

Insights into or solutions for other people's issues were rare among the nine participants. Either the phenomenon is exaggerated in local healing traditions, or it is a culturally dependent phenomenon that might only be relevant to native or local practitioners. It is also possible that certain 
personalities may be more inclined toward this phenomenon, or that it may require extensive experience with ayahuasca that tourists do not generally have, as the local perspective of vegetalism would suggest.

Experiences of connectedness, spiritual confirmation, and answering existential questions suggest that ayahuasca rituals may have some of the described health-related potentials of mystical experiences previously described in the literature; however, the conditions of the individual affinity and the interindividual predictability under ayahuasca remain unclear. This should be better investigated in relation to outcome measures.

The phenomenology of experiences of different subgroups and cultures could be systematically investigated by purposeful case selection as well as other methods, using greater samples. In general, analyzing the possible relation between some of the subjective phenomena of ayahuasca and their outcomes could be helpful in developing ayahuasca supported psychotherapy.

\section{Limitations}

Although theoretical saturation of the coding frame was reached, the small number of participants from only one retreat center may be a limitation since other participants may provide new themes not yet covered in the coding frame. On the other hand, it could be argued that the natural selection of tourists in this study already provides a large heterogeneity of relevant demographic and mental health related variables such as age, educational level, physical and mental preloading, and previous experience with psychotherapeutic thinking. Most participants came from dose, amount, and ratio of the pharmacological components remained uncontrolled. An interpretative uncertainty when defining categories and subsuming units of meaning (single statements) to it lays in the method of QCA. We met this with a determination of reliability.

Another limitation can be seen in the chosen narrative interview method. Although on one hand, an interviewer bias is largely avoided by means of a narrative interview strategy; on the other hand, the method has the disadvantage that areas of interest cannot be explored by hypothesisdriven questioning and therefore may not be reported.

Acknowledgements: TJW contributed in research plan, project management, analyses, and writing up of the manuscript. SR and NN contributed in field work and manuscript revision. TP contributed in critical manuscript revision and provided relevant literature. There is no funding source provided for this article.

Conflict of interest: The authors declare no conflict of interest.

\section{REFERENCES}

Barbosa, P., Giglio, J., \& Dalgalarrondo, P. (2005). Altered states of consciousness and short-term psychological after-effects induced by the first time ritual use of ayahuasca in an urban context in
Brazil. Journal of Psychoactive Drugs, 37(2), 193-201. doi:10.1080/02791072.2005.10399801

Batthyany, A., \& Russo-Netzer, P. (2014). Meaning in positive existential psychology. New York, NY: Springer.

Belser, B., Agin-Liebes, G., Swift, T. C., Terrana, S., Devenot, N., Friedman, H. L., Guss, J., Bossis, A., \& Ross, S. (2017). Patient experiences of psilocybin-assisted psychotherapy: An interpretative phenomenological analysis. Journal of Humanistic Psychology, 57(4), 354-388. doi:10.1177/ 0022167817706884

Beyer, S. V. (2009). Singing to the plants: A guide to Mestizo Shamanism in the Upper Amazon. Albuquerque, New Mexico: University of New Mexico Press.

Bresnick, T., \& Levin, R. (2006). Phenomenal qualities of ayahuasca ingestion and its relation to fringe consciousness and personality. Journal of Consciousness Studies, 13, 5-24.

Cade, B. (1992). A response, by any other... Journal of Family Therapy, 14(2), 163-169. doi:10.1046/j..1992.00449.x

Callaway, J. C., McKenna, D. J., Grob, C. S., Brito, G. S., Raymon, L. P., Poland, R. E., Andrade, E. N., Andrade, E. O., \& Mash, D. C. (1999). Pharmacokinetics of Hoasca alkaloids in healthy humans. Journal of Ethnopharmacology, 65(3), 243-256. doi:10.1016/S0378-8741(98)00168-8

Carhart-Harris, R. L., Erritzoe, D., Haijen, E., Kaelen, M., \& Watts, R. (2018). Psychedelics and connectedness. Psychopharmacolog, 235(2), 547-550. doi:10.1007/s00213-017-4701-y

Carhart-Harris, R. L., \& Goodwin, G. M. (2017). The therapeutic potential of psychedelic drugs: Past, present and future. Neuropsychopharmacology, 42(11), 2105-2113. doi:10.1038/ npp. 2017.84

Cervinka, R., Roderer, K., \& Hefler, E. (2012). Are nature lovers happy? On various indicators of well-being and connectedness with nature. Journal of Health Psychology, 17(3), 379-388. doi:10.1177/1359105311416873

De Rios, M. D. (1972). Visionary vine: Hallucinogenic healing in the Peruvian Amazon. San Francisco, CA: Chandler Publishing.

De Rios, M. D. (1994). Drug tourism in the Amazon. Anthropology of Consciousness, 5(1), 16-19. doi:10.1525/ac.1994.5.1.16

Fiedler, L., Jungaberle, H., \& Verres, R. (2011). Motive für den Konsum psychoaktiver Substanzen am Beispiel des AyahuascaGebrauchs in der Santo-Daime-Gemeinschaft [German: Motives for the use of psychoactive substances using the example of ayahuasca use in the Santo-Daime community]. Zeitschrift für Medizinische Psychologie, 20(3), 137-144. doi:10.3233/ZMP2011-2020

Fotiou, E. (2010). From medicine men to day trippers: Shamanic tourism in Iquitos, Peru (Doctoral dissertation). Department of Anthropology, University of Wisconsin-Madison, Madison, WI, pp. 136-138.

Frankl, V. E. (1986). The doctor and the soul: From psychotherapy to logotherapy. New York, NY: Vintage Books.

Franquesa, A., Sainz-Cort, A., Gandy, S., Soler, J., AlcázarCórcoles, M. Á., \& Bouso, J. C. (2018). Psychological variables implied in the therapeutic effect of ayahuasca: A contextual approach. Psychiatry Research, 264, 334-339. doi:10.1016/j.psychres.2018.04.012

Gasser, P., Kirchner, K., \& Passie, T. (2014). LSD-assisted psychotherapy for anxiety associated with a life-threatening disease: A qualitative study of acute and sustained subjective effects. Journal of Psychopharmacology, 29(1), 1-12. doi:10. 1177/0269881114555249 
Griffiths, R. R., Richards, W. A., McCann, U., \& Jesse, R. (2006). Psilocybin can occasion mystical-type experiences having substantial and sustained personal meaning and spiritual significance. Psychopharmacology, 187(3), 268-283. doi:10. 1007/s00213-006-0457-5

Grob, C. S., McKenna, D. J., Callaway, J. C., Brito, G. S., Neves, E. S., \& Oberlaender, G. (1996). Human psychopharmacology of Hoasca: A plant hallucinogen used in ritual context in Brazil. The Journal of Nervous and Mental Disease, 184(2), 86-94. doi:10.1097/00005053-199602000-00004

Grunwell, J. N. (1998). Ayahuascatourism in South America. MAPS Buletin, 8(3), 59-62.

Helfferich, C. (2011). Die Qualität qualitativer Daten, Manual für die Durchführung qualitativer Interviews. Wiesbaden, Germany: VS Verlag.

Hudson, J. (2011). Ayahuasca and globalization (Undergraduate Honors Theses), p. 14. Retrieved September 15, 2016, from http://scholar.colorado.edu/honr_theses/625

Incayawar, M. (2007). Indigenous peoples in South AmericaInequalities in mental health care. In K. Blui \& D. Bhugra (Eds.), Culture and mental health - A comprehensive textbook (pp. 185-190). London, UK: Holder Arnold.

Jørgensen, C. R. (2004). Active ingredients in individual psychotherapy. Searching for common factors. Psychoanalytic Psychology, 21(4), 516-540. doi:10.1037/0736-9735.21.4.516

Karp, D. A. (2017). Speaking of sadness: Depression, disconnection, and the meanings of illness. Oxford, UK: Oxford University Press.

Kavenská, V., \& Simonová, H. (2015). Ayahuasca tourism: Participants in shamanic rituals and their personality styles, motivation, benefits and risks. Journal of Psychoactive Drugs, 47(5), 351-359. doi:10.1080/02791072.2015.1094590

Kjellgren, A., Eriksson, A., \& Norlander, T. (2009). Experiences of encounters with ayahuasca - "The vine of the soul". Journal of Psychoactive Drugs, 41(4), 309-315. doi:10.1080/02791072. 2009.10399767

Kristensen, K. (1998). The ayahuasca phenomenon: Jungle Pilgrims: North Americans Participating in Amazon Ayahuasca Ceremonies. MAPS. Retrieved October 5, 2016, from http:// www.maps.org/articles/5408-the-ayahuasca-phenomenon

Küsters, I. (2009). Narrative interviews: Grundlagen und Anwendungen [German: narrative interviews: Basics and applications]. Wiesbaden, Germany: VS Verlag für Sozialwissenschaften.

Labate, B. C., \& Pacheco, G. (2011). The historical origns of Santo Daime. In B. C. Labate \& H. Jungaberle (Eds.), The internationalizitation of Ayahuasca (p. 78). Zürich, Switzerland: LIT Verlag.

Lichtenberg, J. D., Lachmann, F. M., \& Fosshage, J. L. (Eds.). (2016). The interpretative sequence. In Self and motivational systems: Towards a theory of psychoanalytic technique (pp. 96-121). New York, NY: Routledge. doi:10.4324/ 9781315798967

Liester, M. B., \& Prickett, J. I. (2012). Hypotheses regarding the mechanisms of ayahuasca in the treatment of addictions. Journal of Psychoactive Drugs, 44(3), 200-208. doi:10.1080/ 02791072.2012.704590

Losonczy, A.-M., \& Mesturini, S. (2010). La Selva Viajera: Rutas del chamanismo ayahuasquero entre Europa y América [The travelling Jungle: Routes of ayahuasquero shamanism between Europe and America]. Religião \& Sociedade, 30(2), 164-183. doi:10.1590/S0100-85872010000200009
Luna, L. E. (1986). Vegetalismo: Shamanism among the Mestizo Population of the Peruvian Amazonas. Acta Universitatis Stockholmensis, Stockholm Studies in Comparative Religion. No. 27 (p. 60). Stockholm, Sweden: Almquist and Wiksell International.

Luna, L. E. (2004). Ayahuasca ritual use. In E. J. Neumann Fridman \& M. N. Walters, (Eds.), Shamanism: An encyclopedia of world beliefs, practices and cultures (pp. 378-382). Santa Barbara, CA: ABC-CLIO.

Luna, L. E. (2005). Narrativas da alteridade: A ayahuasca e o motivo de transformaçaão em animal [Narrative of alteration: Ayahuasca and the motif of transformation into animals]. In B. C. Labate \& S. L. Goulart (Eds.), O uso ritual das plantas de poder [The ritual use of power plants] (pp. 333-354). Campinas, Brazil: Mercado de Letras.

Luna, L. E., \& Amaringo, P. (1999). Ayahuasca visions: The religious iconography of a Peruvian Shaman (p. 38). Berkeley, CA: North Atlantic Books.

Masters, R., \& Houston, J. (1966). The varieties of psychedelic experience. Rochester, VT: Park Street Press (Dell Publishing).

Mattila, A. (2001). "Seeing things in a new light": Reframing in therapeutic conversation. Rehabilitation Foundation, Research Reports 67/2001. Helsinki, Finland: University Press. Retrieved November 2, 2018, from http://citeseerx.ist.psu.edu/viewdoc/ download?doi=10.1.1.128.7389\&rep=rep1\&type=pdf

McKenna, D. J., Towers, G. H., \& Abbott, F. S. (1984). Monoamineoxidase inhibitors in south-american hallucinogenic plants Tryptamine and beta-carboline constituents of ayahuasca. Journal of Ethnopharmacology, 10(2), 195-223. doi:10.1016/0378-8741 (84)90003-5

Mittelmark, B., Sagy, S., Erikson, M., Bauer, G. F., Pelikan, J. M., Lindström, B., \& Espnes, G. A. (2017). Handbook of salutogenesis (p. 268). Cham, Switzerland: Springer.

Passie, T. (2012). Healing with entactogens - Therapist and patient perspectives on MDMA-assisted group psychotherapy (p. 64). Santa Cruz, CA: MAPS.

Patton, M. Q. (2002). Qualitative evaluation and research methods (3rd ed.). Thousand Oaks, CA: Sage Publications, Inc.

Riba, J. (2003). Human pharmacology of Ayahuasca (Doctoral dissertation). Autonomous University of Barcelona, Barcelona, Spain.

Riba, J., Rodriguez-Fornells, A., Urbano, G., Morte, A., Antonijoan, R., Montero, M., Callaway, J. C., \& Barbanoj, M. J. (2001). Subjective effects and tolerability of the South American psychoactive beverage ayahuasca in healthy volunteers. Psychopharmacology, 154(1), 85-95. doi:10.1007/s002130000606

Roediger, E. (2011). Praxis der Schematherapie [German: Practice of schema therapy] (p. 67). Stuttgart, Germany: Schattauer.

Ruf, M., \& Schauer, M. (2012). Facing childhood trauma. Narrative exposure therapy within a cascade model of care. In J. Murray (Ed.), Exposure therapy. New developments (pp. 229-261). New York, NY: Nova Science Publishers.

Schenberg, E. E. (2013). Ayahuasca and cancer treatment. SAGE Open Medicine, 1, 2050312113508389. doi:10.1177/ 2050312113508389

Schreier, M. (2012). Qualitative content analysis in practice. London, UK: Sage.

Schmid, J. T. (2010). Selbst-Behandlungsversuche mit der psychoaktiven substanz ayahuasca: Eine qualitative studie über subjektive theorien zu krankheit, gesundheit und heilung [Treatment Trials with the psychoactive substance 
ayahuasca: A qualitative study of subjective theories on disease, health and healing] (Doctoral dissertation). Saarbrücken, Germany: Südwestdeutscher Verlag für Hochschulschriften.

Shanon, B. (2002). The antipodes of the mind. Charting the phenomenology of the Ayahuasca experience. Oxford, UK: Oxford University Press.

Shanon, B. (2003). Altered states and the study of consciousness: The case of ayahuasca. The Journal of Mind and Behavior, 24(2), 125-154.

Shanon, B. (2014). Moments of insights, healing, and transformation: A cognitive phenomenological analysis. In B. C. Labate \& C. Cavnar (Eds.), The therapeutic use of ayahuasca. Heidelberg, Germany: Springer.
Studerus, E., Gamma, A., \& Vollenweider, F. X. (2010). Psychometric evaluation of the altered states of consciousness rating scale (OAV). PLoS One, 5(8), e12412. doi:10.1371/journal.pone.0012412

Winkelmann, M. (2005). Drug tourism or spiritual healing? Ayahuasca seekers in Amazonia. Journal of Psychoactive Drugs, 37(2), 211.

WMA. (2013). Declaration of Helsinki ethical principles for medical research involving human subjects. Retrieved October 3, 2016, from https://www.wma.net/wp-content/uploads/2016/11/ DoH-Oct2013-JAMA.pdf

Wolff, T. J. (2018). Motivational structure of ayahuasca drinkers in social networks. Journal of Psychedelic Studies, 2(2), 89-96. doi:10.1556/2054.2018.010

Yalom, I. D. (1980). Existential psychotherapy. New York, NY: Basic Books. 